\title{
The Surface of Mars
}

\section{Uncratered Terrains ${ }^{1}$}

\author{
Robert P. Sharp, Laurence A. Soderblom \\ Bruce C. Murray, and James A. Cutts \\ Division of Geological Sciences \\ California Institute of Technology, Pasadena 91109
}

\begin{abstract}
Mariner 6 and 7 photographs reveal two types of uncratered terrain on Mars. These are descriptively termed chaotic and featureless. Chaotic terrain is younger than cratered terrain and displays features strongly suggestive of slump and collapse. The speculation is offered that it may be an expression of geothermal developments within Mars that only recently have begun to affect the surface. Featureless terrain, identified only within the large circular area Hellas, is devoid of any discernible topographic forms larger than the limit of resolution, about 500 meters. Mariner 7 data indicate that Hellas is a topographically low and structurally old basin. Smoothness of its floor could be the product of a recent event or of continuous processes that obliterate craters. Local processes of high efficacy, unusual surface materials, or both, are probably involved. Through its chaotic terrain the martian surface displays a development that does not seem to be recorded, at least in the form of preserved recognizable evidence, on the moon or earth.
\end{abstract}

Cratered terrain [Murray et al., 1971] is the most extensive and enduring surface on Mars. As such, it serves as a datum against which other terrains can be evaluated. Two additional terrain types have been identified on Mariner 6 and 7 frames. They are regarded as distinctly younger than cratered terrain, the product of more recently dynamic surface or near-surface processes, and possibly related to a maturing phase of internal planetary evolution.

To avoid genetic implications, these terrains are descriptively designated 'chaotic' and 'featureless'. Chaotic terrain is an irregular jumble of topographic forms, and featureless terrain is without recognizable topographic configurations. We describe these terrains, advance speculations concerning their relative ages and origins, and examine implications with respect to the evolution of Mars.

Readers will find reference to the individual photo frames at the end of this section useful. The photomosaics and composites accompanying

\footnotetext{
${ }^{1}$ Contribution 1882, Division of Geological Sciences, California Institute of Technology, Pasadena.
}

Copyright (c) 1971 by the American Geophystcal Union. this article are designed to show regional relationships more than specific details.

\section{Chaotic Terrain}

Description. The areas of chaotic terrain recognized to date comprise $1.5 \times 10^{6} \mathrm{~km}^{2}$ within Pyrrhae Regio and adjacent regions centered at about $10^{\circ} \mathrm{S}, 325^{\circ} \mathrm{E}$. Chaotic terrain consists of a rough, irregular complex of short ridges, knobs, and irregularly shaped troughs and depressions best seen on individual frames $6 \mathrm{~N} 6,6 \mathrm{~N} 8$, and $6 \mathrm{~N} 14$ and also shown on Figure 1. The scale of individual features is in kilometers. They display something of a northeasterly grain (6N6), which is accentuated by lighting and foreshortening.

Chaotic terrain appears nearly devoid of recognizable craters. Only three have been tentatively identified, and all are of questionable location. However, craters smaller than $5 \mathrm{~km}$ may be hard to recognize within the jumble of chaotic terrain features. Other crudely circular depressions therein are probably not craters.

Some areas of probable chaotic terrain appear on A frames as brighter than the surroundings, but chaotic terrain is not everywhere uniquely bright. Differences of brightness within chaotic terrain are as great in some instances as the 


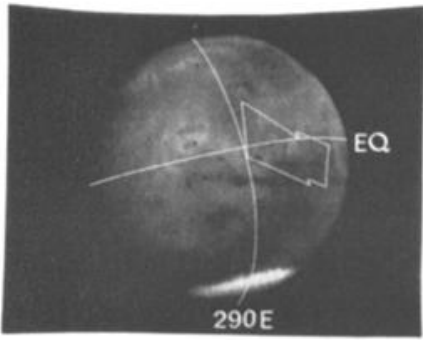

7F69

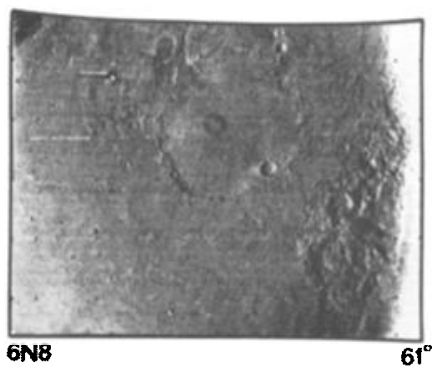

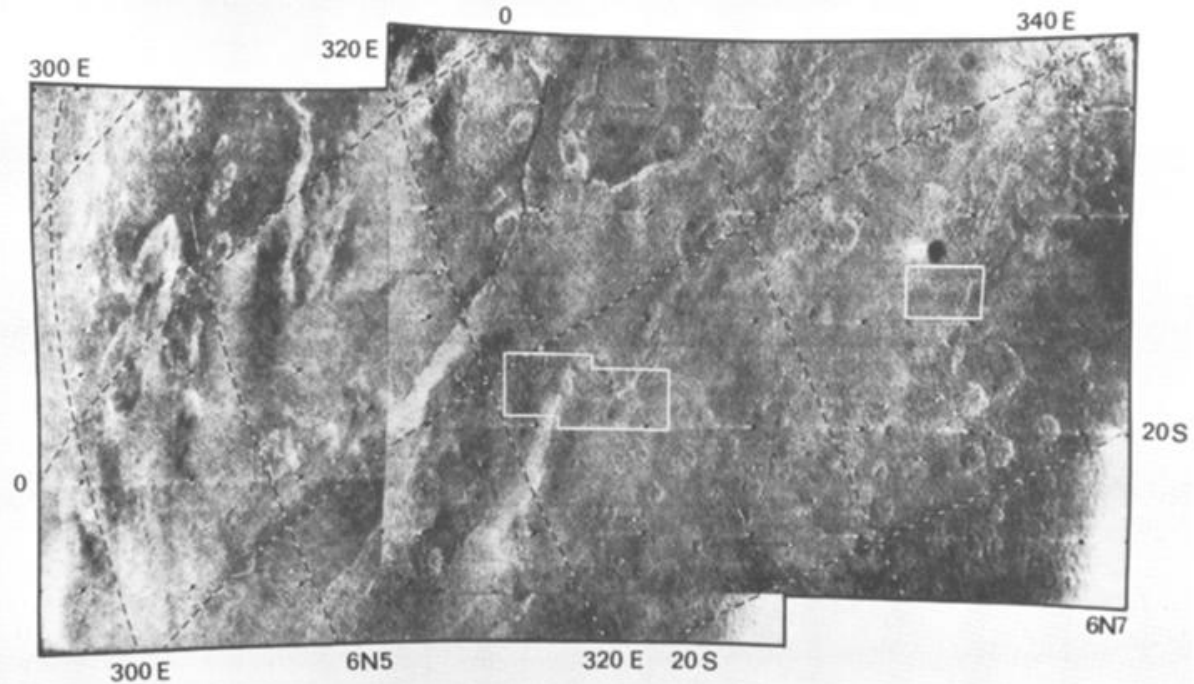
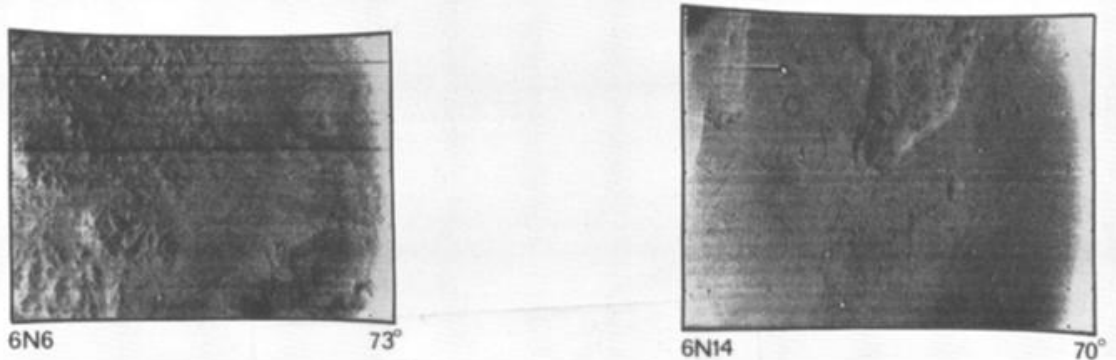

Fig. 1. Mariner $6 \mathrm{~A}$ and $\mathrm{B}$ frames showing chaotic terrain, global location upper right. White rectangles on $A$ frame $6 \mathrm{~N} 7$ indicate location and overlap of $B$ frames $6 \mathrm{~N} 6$ and $6 \mathrm{~N} 14$ in west and location of $6 \mathrm{~N} 8$ in east. Scale, $10^{\circ}$ latitude and longitude, roughly $590 \mathrm{~km} .6 \mathrm{~N} 6,158 \times 108 \mathrm{~km}$; $6 \mathrm{~N} 14,236 \times 96 \mathrm{~km} ; 6 \mathrm{~N} 8,125 \times 96 \mathrm{~km}$. Sun angles above horizon at lower right of $\mathrm{B}$ frames.

differences between chaotic and cratered terrains.

Distribution. Chaotic terrain was initially recognized on $\mathrm{B}$ frames $6 \mathrm{~N} 6,6 \mathrm{~N} 8$, and $6 \mathrm{~N} 14$, to a total combined area of $12,500 \mathrm{~km}^{2}$. Improved processing of $\mathrm{A}$ frames subsequently revealed the distinctive topographic texture of chaotic terrain over a greater area.

By tracing contacts between chaotic and cratered terrains from $B$ frames onto the enclosing $\mathrm{A}$ frames and by extending these contacts on the basis of structural patterns, crater 
distribution, brightness contrasts, and characteristic regional trends, a map of possible chaotic-terrain distribution in A frames 6N5, $6 \mathrm{~N} 7$, and $6 \mathrm{~N} 9$ has been constructed (Figure 2). This map shows approximately $1.5 \times 10^{6} \mathrm{~km}^{2}$ of chaotic terrain, irregularly distributed in oddshaped patches, displaying something of an elongation to the northeast that is accentuated by the obliqueness of view. The mapping procedure is subjective, so Figure 2 is, at best, an approximation. $\mathrm{CO}_{2}$ pressures recorded by the Mariner 6 infrared spectrometer [Herr et al., 1970] suggest unusual topographic roughness in this region.

The chaotic terrain recognized on Mariner 1969 photos lies within an equatorial belt extending between $15^{\circ} \mathrm{S}$ and $15^{\circ} \mathrm{N}$. A conclusion that this terrain is confined to equatorial latitudes is premature, however, for much less than
$1 \%$ of the martian surface has been photographed adequately to reveal its presence. Irregular streaky patterns on Mariner 4 frame 2 hint at the possible existence of chaotic terrain in the vicinity of $25^{\circ} \mathrm{N}$. Recognized chaotic terrain is centered in the mixed light and dark area Pyrrhae Regio and appears to extend at least modest distances westward into dark Aurorae Sinus, northeasterly into dark Margaritifer Sinus, and northward into light Chryse. The northern tip of Margaritifer Sinus may be defined by a contact between chaotic terrain, to the north, and cratered terrain (see SW part of $6 \mathrm{~N} 9$ ).

Geometrical relationship to cratered terrain. Where the chaotic-cratered terrain contact is clearly shown, as on $6 \mathrm{~N} 7,6 \mathrm{~N} 8,6 \mathrm{~N} 9$, and $6 \mathrm{~N} 14$, it is planimetrically irregular but well defined. In places $(6 \mathrm{~N} 6,6 \mathrm{~N} 8)$, the topography immediately to the chaotic side displays features re-

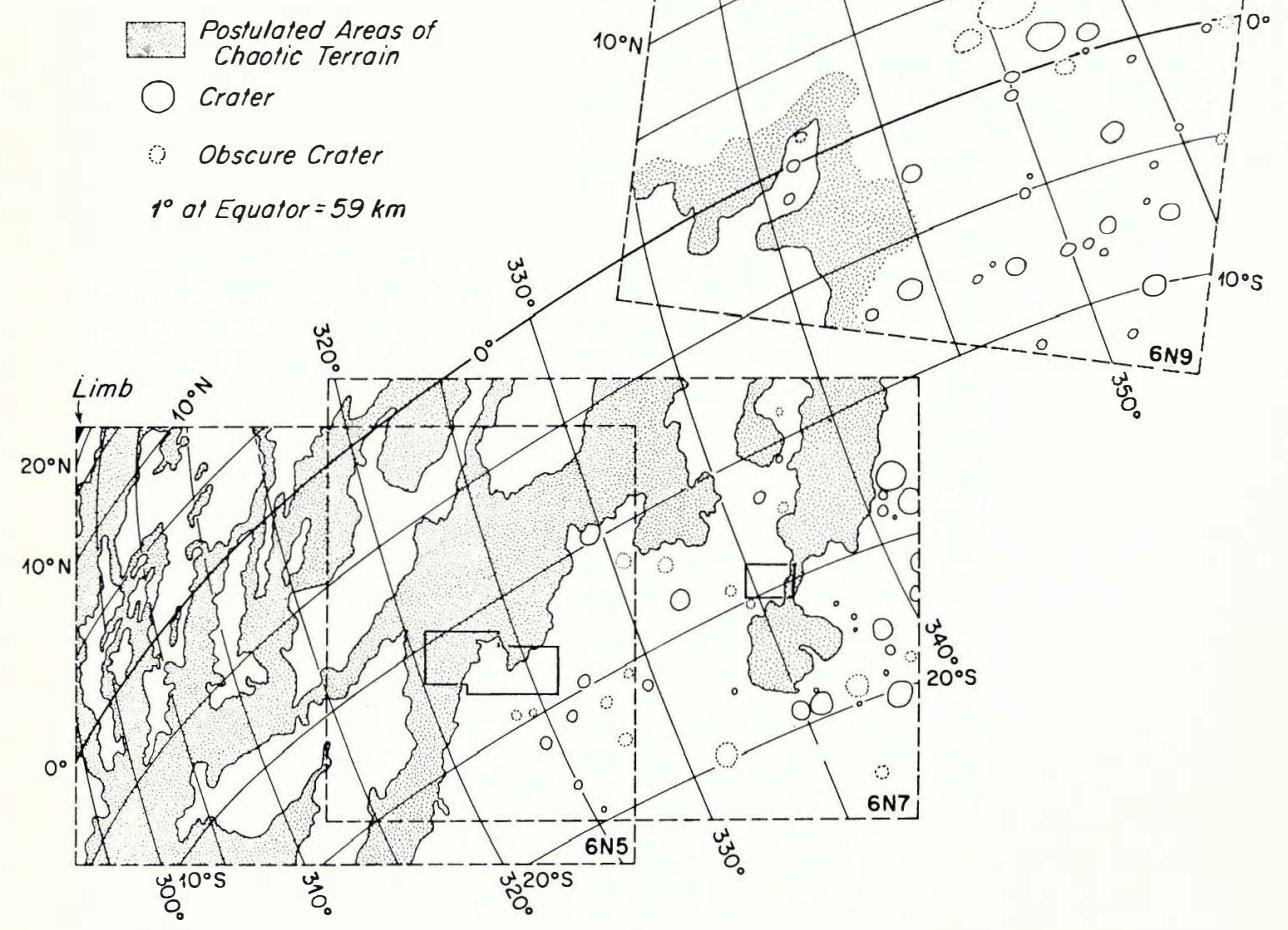

Fig. 2. Interpretive map of chaotic-terrain distribution constructed from Mariner 1969 photos. Compare Figure 1 for location of $\mathrm{B}$ frames and other details. 
sembling arcuate break-away scarps, arcuate blocks and ridges, and intervening irregularly shaped depressions. Extending into cratered terrain away from the contact are irregular, subparallel markings that look like huge cracks. Examples are south of the valley in $6 \mathrm{~N} 14$ and west of the contact in $6 \mathrm{~N} 8$.

Wherever relationships are well displayed $(6 \mathrm{~N} 14,6 \mathrm{~N} 8)$, areas of chaotic terrain appear lower than the adjoining cratered surface, and this is confirmed by $\mathrm{CO}_{2}$ data [Herr et al., 1970]. Furthermore, these data and radar observations [Anonymous, 1970, p. 30] indicate that chaotic terrain occupies a regionally low area.

Relative age. Low elevation, contact configuration, and the marginal features of chaotic terrain plus the surface markings (cracks?) on adjoining cratered surfaces suggest that chaotic terrain formed at the expense of cratered terrain. If this is a valid conclusion, chaotic terrain must be younger. Further, the chaotic terrain formed after the interval that reduced the relief of flat-floored craters, for such modification would surely have destroyed the fresh, sharp features of chaotic terrain.

The paucity of craters in chaotic terrain suggests that it is a relatively late development in martian history. Insofar as craters larger than $15 \mathrm{~km}$ across are concerned, this is a reasonable conclusion. For small, bowl-shaped craters relationships are less clear. The number of bowl-shaped craters on surfaces adjoining chaotic terrain in $6 \mathrm{~N} 8$ and $6 \mathrm{~N} 14$ suggests that the area of a chaotic terrain shown on B frames should display at least 6 or 7 bowl-shaped craters. Only three marginal examples are identified. Considering the difficulty of identifying small craters within areas of chaotic terrain, this difference, by itself, is hardly enough to establish a young age for chaotic terrain, but coupled with the probable youth of bowl-shaped craters [Murray et al., 1971], it is strongly suggestive.

Terrestrial and lunar analog. Understanding of chaotic terrain is sought through comparison with possibly analogous phenomena on the moon and carth. Thoughts turn naturally to meteorite impacts and volcanic explosions, one or possibly both of which have formed areas of irregular hummocky terrain on the moon, as, for example, in parts of the ejecta sheet along the southern rim of Mare Imbrium (Montes Apenninus and Mare Vaporum quadrangles) and in the rough area immediately southeast of the Alpine Valley (Cassini quadrangle, south). Similarities exist between these lunar areas and martian chaotic terrain, but the dissimilarities are even greater. The distribution pattern, gross geometry, and particularly the inset position of chaotic terrain are not characteristic of an ejecta sheet.

On earth some accumulations of volcanic material display highly irregular topographic forms, which, on a small scale and as individual features, resemble some aspects of chaotic terrain. In larger view, the volcanic phenomena are hardly comparable in distribution pattern, and they are not at all comparable in the topographically inset relationship. Marginal slump blocks and extramarginal fractures are not particularly characteristic of lava accumulations. Large-scale collapse is, of course, commonly associated with volcanism [Williams, 1941; Cotton, 1944], but the structures developed, caldera and volcano-tectonic depressions, do not have the geometric form or distribution displayed by areas of martian chaotic terrain.

Complex dune sheets have topographic forms resembling somewhat the ridge and trough pattern of some chaotic terrain $(6 \mathrm{~N} 6)$, the Tifernine dunes of Algeria for example (P. D. Lowman, personal communication, 1969). However, individual dunes within such complexes are on a considerably smaller scale than the ridges and troughs of chaotic terrain. Even when allowances are made for differences in gravity, atmospheric density, grain size, wind velocity, and similar factors, it seems unlikely that martian transverse dunes, if they exist, will be several times larger than their earthly counterparts.

The arcuate breakaway scarps, rotated blocks, parallel ridges, closed depressions, jumbled aspect, and surface cracks (?) associated with chaotic terrain are all features found in slump, slide, or collapse areas on earth. The chaos valley of $6 \mathrm{~N} 14$ looks like a feature that has extended itself headward and sidewise into cratered terrain, and the transition zone between cratered and chaotic terrains shown on $6 \mathrm{~N} 8$ displays the characteristics of a slump zone on earth, although the scale is unusually large.

It appears that nothing currently known on the moon or earth is wholly analogous to martian chaotic terrain. However, many of its characteristics are similar to features produced by or associated with terrestrial collapse, slumps, 
slides, or other forms of mass movement. The problem is to find explanations for possible large-scale mass movements on Mars occurring after what appears to have been a considerable period of relative stability during which the ancient cratered terrain was greatly modified.

Origin. Before considering events, processes, or influences that could have generated such mass movements, the nature of the materials involved merits attention. The abundance and sizes of craters [Murray et al., 1971] suggest that the martian surface should be mantled to a depth of several hundred meters by a loose impact rubble, and that rocks of the crust should be shattered to still greater depths. Rubble is used here to designate a loose jumble of fragmented rock debris of all particle sizes, which may not have been transported any significant distance from the original bedrock source. Under proper conditions such rubble could undergo mass movements, even on modest slopes.

Among processes of external origin that might cause mass movements, the most obvious is meteorite impact. Vibrations generated by large impacts could presumably induce movement within a mantle of loose rubble resting on regional slopes. The problems are to develop regional slopes and to provide enough large impacts to form chaotic terrain at some considerable time after development of the ancient cratered surface. Regional slopes can be formed by internal diastrophism, and it is a permissible speculation that this has occurred. However, younger craters on Mars all seem to be less than about $16 \mathrm{~km}$ in diameter, and it is debatable whether impacts forming craters of this size are great enough to cause slumping, sliding, or creep on the scale displayed by chaotic terrain. Although radar [Anonymous, 1970; Rogers et al., 1970; Goldstein et al., 1970] and $\mathrm{CO}_{2}$-pressure data [Belton and Hunten, 1969; Wells, 1969] show that extensive regional slopes exist on Mars, they are for the most part inclined at only a fraction of a degree [Herr et al., 1970]. Nothing is known about their age, and they may be as old as the primordially cratered terrain itself. Mass movement on regional slopes motivated solely by meteorite impacts has serious drawbacks as the principal cause of chaotic terrain.

Although further explorations of Mars may show that chaotic terrain is not limited to equatorial regions, the strong development there and the association with a topographically low region [.1 nonymous, 1970; Herr et al., 1970] suggest that climatological change might be a genetic factor. If Mars had earlier developed large bodies of segregated ground ice, climatic amelioration might cause decay of such bodies to occur earliest in low areas within equatorial regions. Decay of segregated bodies of ice, not just the thawing of perennially frozen ground, would be needed to produce the degree of collapse required. Under current martian atmospheric conditions any melt water formed would quickly evaporate, if it approached the surface.

The inset relationship of chaotic terrain implies removal of material by some means either downward, laterally outward, or upward. A mechanism for upward removal of solid materials coming readily to mind is deflation by wind. On earth, deflation has produced large hollows, and slumping around the margins of such depressions might produce features like those seen along the margins of chaotic terrain. The large chaos valley of $6 \mathrm{~N} 14$ might conceivably be part of a deflation hollow modified by marginal slumping. However, deflation on earth has never, to the best of our knowledge, produced an area of topography like that shown on $6 \mathrm{~N} 6$.

Among internal factors, volcanism is a priori one of the more attractive. Extrusion of volcanic material is a principal cause of large-scale collapse on earth, commonly accompanied by marginal slumping and ground cracking. However, the geometrical patterns and distribution of chaotic-terrain areas are so unlike anything known to result from volcanic collapse as to argue against this as a sole mechanism. However, loose rubble might be set into movement on regional slopes if vibrated by volcanic explosions or fluidized by volcanic gases rising surfaceward under pressure.

A major problem with internal factors is to find a way of bringing them into play at some significant time after development and extensive modification of cratered terrain surfaces. In this context the geothermal evolution of Mars deserves consideration. Studies of this matter (MacDonald [1962], Anderson and Phinney [1967], Anderson [1969], and Hanks and Anderson [1969], to cite just a few) are necessarily theoretical, highly speculative, and involve different models, but they indicate that Mars may never have attained a molten stage. This is contrary 
to the conclusions of Binder [1969b]. Be that as it may, one model suggests that a condition of partial melting accompanied by differentiation, degassing, tectonism, and volcanism may be anticipated about $0.5 \times 10^{9}$ years hence [Anderson and Phinney, 1967]. The legion of assumptions involved in these calculations is such that the timing can only be approximate.

This raises the intriguing thought that Mars may just now be reaching that stage in its geothermal evolution in which some of the above discussed internal processes are coming into play. They could affect the surface through melting and evaporation of segregated masses of ground ice, through volcanic collapse accompanied by extrusion elsewhere, through fluidization by gaseous discharge, or by tectonic deleveling of the crust, all or any of which might have helped to create chaotic terrain. This is admittedly pure speculation based on a thermal model of Mars not acceptable to all investigators [Binder, 1969b].

Implications of chaotic terrain. The oldest, most enduring surface on Mars is heavily cratered [Murray et al., 1971]. Chaotic terrain is clearly younger. Something unusual has happened within areas of chaotic terrain to generate distinctive topographic configurations at the expense of cratered terrain. Chaotic terrain is either the product of a recent happening, or it is the result of a continuing activity sufficient to destroy most craters and yet has remained confined geographically.

Martian chaotic terrain exceeds in scale anything similar known on earth, and it seems to have no recognizable analog on the lunar surface. Mars may be undergoing a development either never experienced by the moon or possibly masked by formation of the lunar maria. If earth experienced a similar development, the surface evidence has been erased.

If the speculation that martian chaotic terrain is an early expression of geothermal maturing of the planet has validity, Mars may be entering on a stage in its evolution that could profoundly alter its surface characteristics and environment through deformation, degassing, and volcanism. As earlier hinted by Urey [1956], the most interesting time for Mars may still be ahead.

\section{Featureless Terrain}

Definition, description, and distribution. Fea- tureless terrain is devoid of recognizable topographic configurations at the effective 500-meter limit of resolution of 1969 Mariner photographs. However, it may prove to be anything but smooth on closer observation. Featureless terrain displays some irregular, diffuse variations in shading, possibly the result of gently undulating topography or of albedo differences. To qualify as featureless, a region should be devoid of discernible topographic forms over at least $10,000 \mathrm{~km}^{2}$, as small areas of intercrater surface within regions of cratered terrain appear to be smooth even at B-frame resolution.

The bright circular region Hellas, roughly $1700 \mathrm{~km}$ across and centered at about $70^{\circ} \mathrm{E}$ and $45^{\circ} \mathrm{S}$, contains at least $1.6 \times 10^{6} \mathrm{~km}^{2}$ and possibly $2.5 \times 10^{6} \mathrm{~km}^{2}$ of contiguous featureless terrain. Featureless terrain may be widely distributed over the surface of Mars, but at present only the Hellas area is known to qualify. A relationship between featureless terrain and the nature, origin, and behavior of Hellas is implied.

Hellas. Hellas is one of the largest and most nearly circular features on Mars (Figure 3). At times it is one of the brightest, occasionally being mistaken for the south polar cap [Lowell, 1906]. The luminance of Hellas varies secularly as well as seasonally and diurnally. It is usually brightest in the late afternoon, especially during southern winters when the polar cap is at maximum. At other times it fades into the background of surrounding darker areas irrespective of diurnal or seasonal relationships. The extreme brightness of Hellas has been attributed to clouds or frost [Lowell, 1906; Collinson, 1953; Michaux, 1967]. Its prevailing ground color is markedly pinkish [Lowell, 1906; Antoniadi, 1930].

Mariner $7 \mathrm{~A}$ frames cover about $65 \%$ of Hellas. They show its interior to be a monotonous surface with just three clearly discernible craters at its western edge (7N27). Highly processed versions of $7 \mathrm{~N} 29$ show one or two indeterminate markings that might be taken for craters closer to the center of Hellas.

Transition zone, Hellas to Hellespontus. Hellas is bordered on the west by Hellespontus, a dark area of heavily cratered terrain (Figure 4). The Mariner 7 phototrack crossed the transition zone between Hellas and Hellespontus at about $45^{\circ} \mathrm{S}$. The western or Hellespontus edge of this zone is sharply defined by a series of discontinous overlapping scarps and narrow ridges, individ- 
Surface of Mars-Uncratered Terrains

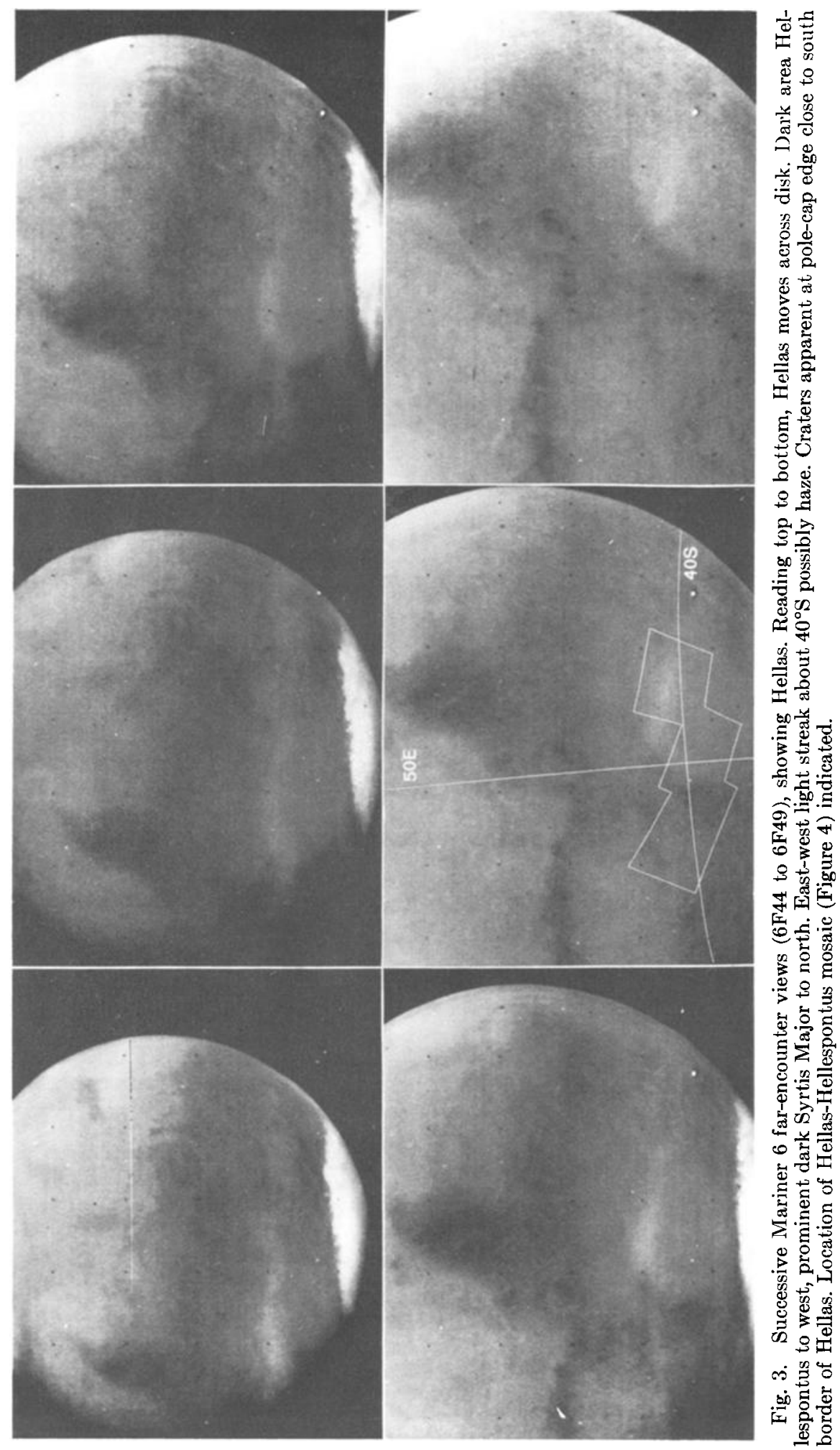




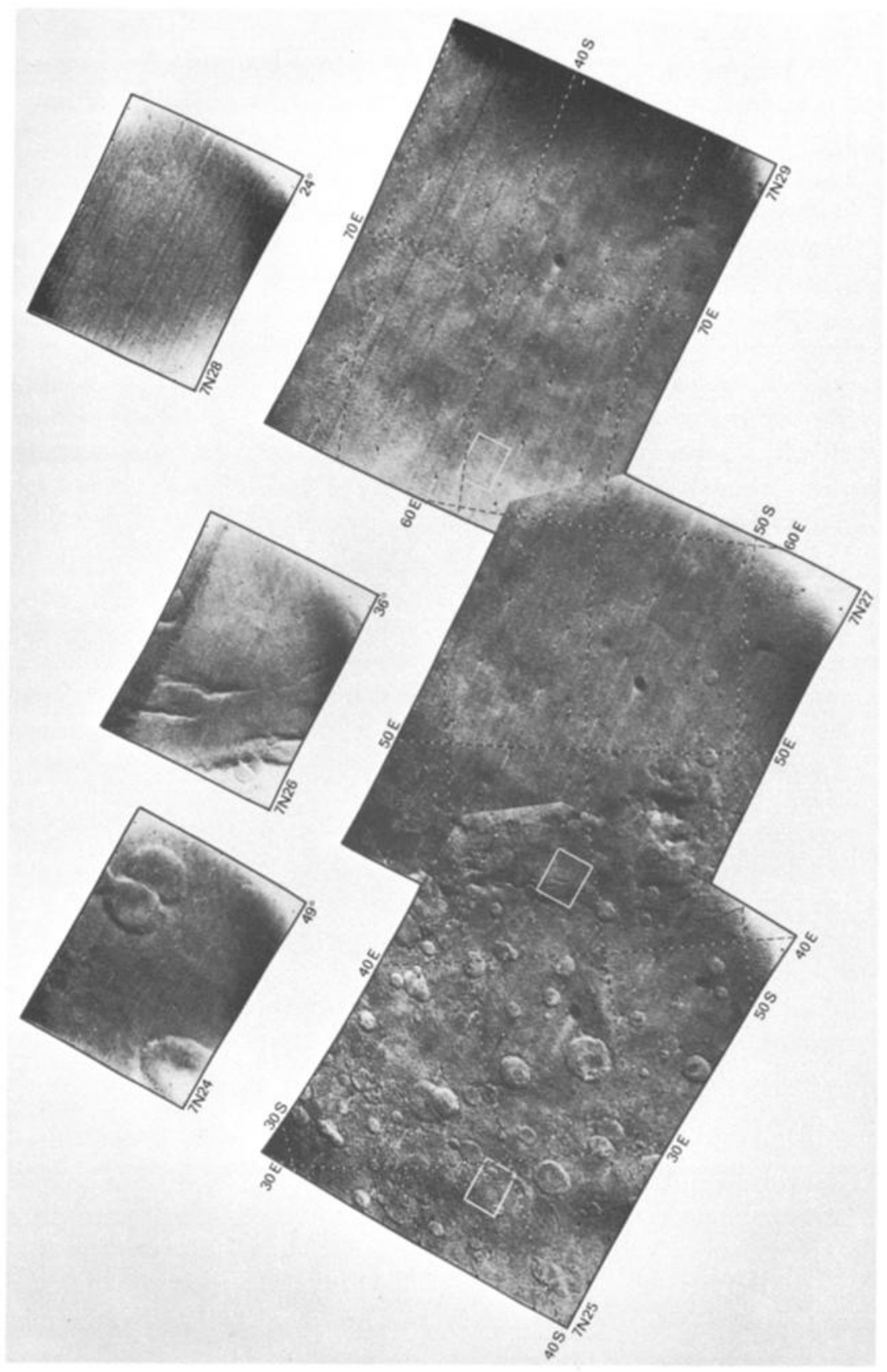

蛋

娄合

馬

象

$x$

密

出

छํํㄴ

范

字亮

要

․ㅗㅇ

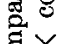

g $X$

용

공

遇

政

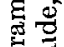

焉

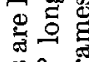

क⿺辶万木

군

氜

웅

.

范

옹으

可

옳

車里

ब्\zh14

政

옹

行

駊㻤

包焉

声跤

$0 \%$

\& $x$

政

焉

下

岁学令

.

晋

+

क्ष $x$

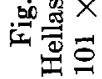


ually $20-90 \mathrm{~km}$ long. The eastern edge of the zone is marked by an abrupt but a planimetrically irregular albedo contrast from dark within the zone to light on the adjacent Hellas surface (7N27).

The transition zone, 150 to $325 \mathrm{~km}$ wide, is characterized by a number of narrow, irregularly linear ridges and a few scarps paralleling the borders. This zone has craters comparable in abundance to adjacent Hellespontus, except that local areas $(7 \mathrm{~N} 26)$ are poor in small craters. Nowhere do the scarps or ridges crosscut flat-bottomed craters; rather, the craters appear to interrupt or deform the ridges.

Relative elevation of Hellas and Hellespontus. Some observers have concluded that Hellas stands high because its variable brightness is the result of clouds or frost [Collinson, 1953; Tombaugh, 1968]. However, recent arguments that frost on Mars may favor low rather than high places, although not universally accepted [Binder, 1969a], challenge that interpretation [Sagan and Pollack, 1966, 1968; O'Leary and Rea, 1967]. Mariner 7 furnishes the following data indicating that Hellas is a depression.

1. The form of the transition zone, with a linear western border determined by scarps and ridges and an irregular eastern edge defined by differences in luminance, suggest that it is inclined eastward, down toward Hellas. The configuration of the contact between the transition zone and the Hellas surface (7N27) resembles that seen at the foot of slopes experiencing creep where they intersect a gentler surface.

2. Insofar as is discernible, all scarps within the transition zone face eastward, down toward Hellas.

3. The ingoing radio occulation of Mariner 7 occurred over the southern tip of Hellespontus at $58^{\circ} \mathrm{S}$ and $30^{\circ} \mathrm{E}$. It indicated an atmospheric pressure of only $3.8 \mathrm{mb}$, showing that this point on Hellespontus is well above the average level of the martian surface [Kliore et al., 1969].

4. $\mathrm{CO}_{2}$-pressure data from the Mariner 7 infrared spectrometer [Herr et al., 1970] indicate that Hellas lies $5.5 \mathrm{~km}$ lower than Hellespontus and that the transition slope is inclined $0.7^{\circ}$ $0.8^{\circ}$ eastward. Hellas was the lowest part of the martian surface traversed by the Mariner 1969 spacecraft, $8 \mathrm{~km}$ lower than the highest point recorded.
Mariner $7 \mathrm{~A}$ frames show only $15 \%$ of the Hellas border. Extrapolations from small samples are necessarily tenuous, but the circularity of Hellas suggests that it is a coherent structure with consistent border characteristics. This interpretation is supported by $\mathrm{CO}_{2}$-pressure data indicating highlands both to east and west and by far-encounter frames showing cratered terrain along the south edge of Hellas at the pole-cap margin (Figure 3). Thus Mariner 7 data indicate that Hellas is a large circular depression, not just an albino freckle on the surface of Mars. Infrared spectrometer data [Herr et al., 1970] suggest that the floor is reasonably flat, but ultraviolet spectrometry suggests that it rises eastward [Hord and Barth, 1971].

Origin of Hellas. At least three modes of origin merit consideration; impact, volcanic explosion, and subsidence. Nothing on Mariner 7 photos forces a choice between these possibilities or suggests other alternatives. Analogy with lunar features may favor impact. If the Hellas structure is the product of impact, it represents an occurrence larger than anything known on the moon. The outer ring of Mare Imbrium, $1100 \mathrm{~km}$ across, is about $65 \%$ the diameter of Hellas.

No terrestrial volcanic caldera or tectonovolcanic depression [Williams, 1941; Cotton, 1944] approaches Hellas in size. However, a basin of this magnitude might result from isostatic subsidence over a dense mass within the crust or near crustal interior [O'Leary et al., 1969]. The low elevation of Hellas, roughly $2 \mathrm{~km}$ below the general level of the martian surface [ $\mathrm{Herr}$ et al., 1970], is consistent with this interpretation. Such a mass might be an undigested inhomogeneity inherited from the planet's early accretionary phase.

Age of Hellas. Whatever its origin, Hellas, as a structural feature, appears to be very old. If it is of impact or volcanic explosive origin, all signs of an ejecta rim and of ejecta sheets have been obscured or eliminated. Indeed, they would have to be older than the heavily cratered terrain of Hellespontus, which is regarded as basically accretionary [Murray et al., 1971]. Further, the scarps and ridges of the transition zone, which appear to be structures related to the formation of Hellas, are older than the craters of the transition zone. They do not crosscut the craters; rather, they are distorted by them (7N25, 7N26, 7N27). Thus, Hellas as a structural 
feature had its origin quite early in the history of the planet. Although the Hellas structure is very old, its present floor has experienced more recent activity that continues to obliterate craters.

The cloud or haze problem. Mariner 6 and 7 near-encounter photos show Mars to have been largely if not completely free of optically thick clouds along the flight path. The only features even remotely resembling thick clouds lie over or along the margins of the south polar cap. Even they are suspect owing to the lack of shadows and cloud-like structures [Leovy et al., 1971]. Nonetheless, the possibility should be considered that the floor of Hellas was obscured by ground clouds or haze when photographed by Mariner 7 . The clarity of features in the transition zone indicates that such a cloud would have to be right down on the Hellas floor.

No significant difference in brightness is detectable between the crater-free floor of Hellas and the marginal area where the three craters are visible (7N27). If a ground fog or haze were obscuring craters, it must have had the same photometric properties as the ground itself. A dust cloud is, perhaps, the most likely possibility, but why should it be so sharply confined to the Hellas floors? Mariner 6 far-encounter frames (Figure 3) show an irregular bright streak extending eastward across the face of the planet at about $40^{\circ} \mathrm{S}$, passing over the north part of Hellas. This may be haze, but if so it was not localized over Hellas. At the time of Mariner 1969 flyby, ground-based astronomical observations showed Hellas to be in a relatively somber state.

These relationships combine to create doubt that the lack of visible craters over most of the Hellas floor is due to obscuration by clouds or haze. A ground surface devoid of discernible topographic forms is considered more likely and is assumed as a basis for further discussion.

Origin of the featureless surface of Hellas. Some degree of crater formation has probably prevailed on Mars nearly up to the present. The lack of craters within featureless terrain could indicate a recent event that has swept the surface clean or a continuing activity capable of obliterating craters as rapidly as they are formed. The ancient age of Hellas, as a structural feature, requires that any such recent event or continuing process be nearly coextensive with the Hellas floor, or that they be effective only there.

Episodic events that might be considered include extrusions of volcanic ash or tuff, fluidization of surface rubble by emanating volcanic gases, accentuation of surface creep by geothermal change, recent deterioration of frozen ground [Leighton and Murray, 1966], or an atmospheric cometary explosion. Continuing processes meriting consideration could include transport and deposition by wind, unusually effective basal surges associated with impacts [Roberts and Carlson, 1962; Moore, 1967; Fisher and Waters, 1970], continuous creep of unusual efficacy, or something associated with the unusual brightening of Hellas. If basal surges were involved, Hellas should display at least a few scattered craters.

Hellas is exceptionally low, $2 \mathrm{~km}$ below the martian mean elevation [Herr et al., 1970], and it is located in far southern latitudes. The low elevation might cause it to be effected by the hypothecated internal warming of the planet earlier than other parts of the surface. This condition could activate some of the episodic events listed above. Or the combination of low elevation and proximity to the pole-cap edge might produce winds of unusual force, frequency, and duration within Hellas (C. B. Leovy, personal communication, 1970).

Whether or not special environmental conditions obtain in Hellas, there is clearly something unusual about its surface. Perhaps it is the nature of the surface material. Much of Mars is presumably mantled with an impact rubble or material derived therefrom. The surface mantle of Hellas may have different physical properties, possibly those of a lightweight material such as a finegrained pumice, which could respond with unusual facility to processes of any type, episodic or continuing, at work on the martian surface. An inclination to regard Hellas simply as a dust-filled basin is partly dampened by the sharpness of the contact with the transitional slope.

The origin of featureless terrain remains a highly speculative topic. A combination of several of the processes and conditions enumerated may hold the answer. The thought that Hellas may be mantled by a type of material markedly different from that covering other parts of the martian surface has the appeal of simplicity. 
In any case, it is clear that Hellas is the site of an ancient event, the creation of a $1700-\mathrm{km}$ circular structure; it is also the locale of some unusual combination of surface processes and material that continue to obliterate craters at an enormously faster rate than on most other parts of the martian surface.

\section{Comments Pertinent to the Marinhr 1971 Mars Missions}

Chaotic and featureless terrain enhance the attractiveness of Mars as a subject for exploration by the Mariner orbiter flights of 1971 . Attempts should be made to obtain a more extended high-resolution coverage of chaotic terrain with the objectives of: (1) demonstrating that the individual features and areas identified on B frames $6 \mathrm{~N} 6,6 \mathrm{~N} 8$, and $6 \mathrm{~N} 14$ are parts of a single terrain type and not isolated unrelated phenomena, (2) determining the number of craters within chaotic terrain as a possible means of giving some indication of its relative age, (3) showing in more detail features within the transition zones between cratered and chaotic terrains and more of the individual topographic forms within chaotic terrain, with the aim of contributing to an understanding of its origin, (4) showing whether the extension westward of chaotic terrain (Figure 2) from the type area in $6 \mathrm{~N} 7$ is valid, and (5) exploring other parts of the planet for other regions of chaotic terrain.

With respect to featureless terrain, Mariner 1971 photography could be profitably exercised to show: (1) whether other large circular bright areas on Mars harbor featureless surface, (2) whether featureless terrain is limited to such circular areas or exists in other geometrical, structural, or topographic situations, (3) what the structural and topographical relationships are to cratered terrain, and (4) further relationships that may throw light on the genesis of featureless terrain.

Both chaotic and featureless terrain merit particular attention during the Mariner Mars 1971 missions because they appear to be among the youngest and most dynamic parts of the martian surface. This makes them especially attractive as places in which to search for unusual surface environments.

\section{Concluston}

The uncratered terrains of Mars do not seem to be duplicated on the moon. This contrast can be attributed principally to differences in constitution, internal evolution, and the existence of a martian atmosphere. Cratering has been the principal process creating and modifying the topographic features of both bodies, and the extensive remnants of accretionary cratered surface on Mars establish it as more like the moon than the earth. However, it is an intriguing speculation that in future eons Mars will become more like earth as it progresses to an advanced state of geothermal maturity.

Acknowledgments. We are deeply indebted to all persons whose combined efforts made the Mariner 1969 flights to Mars a success. With respect to the series of four articles on martian surface features published herein, we specifically acknowledge the valuable aid of the following: G. E. Danielson, S. A. Collins, J. J. van der Woude, T. C. Rindfleisch, J. A. Dunne, R. C. Dewar, and Patricia Conklin, all of the California Institute of Technology and JPL. Our colleagues of the Mariner TV team, M. E. Davies, A. H. Herriman, N. H. Horowitz, C. B. Leovy, B. A. Smith, and A. T. Young have provided counsel and information. Without the leadership and unending efforts of principal investigator, R. B. Leighton, the TV project would never have succeeded.

The participation of Murray, Leighton, and Sharp has been underwritten by the California Institute of Technology. Cutts has been partly supported by NASA-105-69836 and Soderblom by NGI $-05-002-003$.

\section{References}

Anonymous, Radar Studies of Mars, Final Rep., NASA Contract NAS 9-7830, 79 pp., MIT Lincoln Lab., 1970.

Anderson, D. L., The evolution of terrestrial-type planets, Appl. Opt., 8, 1271-1277, 1969.

Anderson, D. L., and R. A. Phinney, Early thermal history of the terrestrial planets, in Mantles of the Earth and Terrestrial Planets, edited by S. K. Runcorn, pp. 113-126, Interscience, New York, 1967.

Antoniadi, E. M., La Planète Mars, 239 pp., Librairie Scientifique Hermann, 1930.

Belton, M. J. S., and D. M. Hunten, Spectographic detection of topographic features on Mars, Science, 166, 22,j-227, 1969.

Binder, A. B., Topography and surface features of Mars, Icarus, 11, 24-35, $1969 a$.

Binder, A. B., Internal structure of Mars, $J$. Geophys. Res., 74, 3110-3118, $1969 b$.

Collinson, E. H., The planet Mars, J. Brtt. Astronom. Soc., 64, 4-17, 1953.

Cotton, C. A., Volcanoes as Landscape Forms, 416 pp., Whitcombe and Tombs, London, 1944.

Fisher, R. V., and A. C. Waters, Base-surge bed forms in maar volcanoes, Amer. J. Sci., 268 , $157-180,1970$. 
Goldstein, TR. M., W. G. Melbourne, G. A. Morris, G. S. Downs, and D. A. O'Handley, Prelıminary radar results of Mars, Radio Scl., 5, 475-478, 1970.

Hanks, T. C., and I). L. Anderson, The early thermal history of the earth, Phys. Earth Planet. Interiors, 2, 19-29, 1969.

Herr, K. C., I). Horn, J. M. MeAfee, and G. C. Pimentel, Martian topography from Mariner 6 and 7 infrared spectra, Astrophys. J., 75, 883-884, 1970.

Hord, C. W., and C. A. Barth, Mariner 6 and 7 ultraviolet spectrometer results, in press, 1971.

Kliore, A., G. Fjeldbo, and B. L. Seidel, Mariner 6 and 7: Radio occultation measurements of the atmosphere of Mars, Science, 166, 1393-1397, 1969.

Leighton, R. B., and B. C. Murray, Behavior of carbon dioxide and other volatiles on Mars: Science, 158, 136-144, 1966.

Leighton, IR. B., N. H. Horowitz, B. C. Murray, R. P. Sharp, A. H. Herriman, A. T. Young, B. A. Smith, M. E. Davies, and C. B. Leovy, Mariner 6 and 7 television pictures: Preliminary analysis, Science, 166, 49-67, 1969.

Leovy, C. B , B. A. Smith, A. T. Young, and R. B. Leighton, Mariner Mars 1969: Atmospheric results, J. Gcophys. Res., 76, this issue, 1971.

Lowell, Percival, Mars and Ils Canals, 393 pp., Macmillan, New York, 1906.

Macloonald, G. J. F., On the internal constitution of the inner planets, J. Geophys. Res., 67, 2945$2974,1962$.

Michaux, C. M., Handbook of the Physical Properlies of the Planet Mars, 167 pp., NASA SP3090, 1967.
Moore, J. G., Base surge in recent volcanic eruptions, Bull. Volcanol., 30, 337-363, 1967.

Murray, B. C., L. A. Soderblom, R. P Sharp, and J. A. Cutts, The surface of Mars, 1, Cratered terrain, J. Geophys. Res., 76, this issue, 1971.

O'Leary, B. T., and D. G. Rea, Mars: Influence of topography on formation of temporary bright patches, Science, 155, 317-319, 1967.

O'Leary, B. T., M. J. Campbell, and C. Sagan, Lunar and planetary mass concentrations, Science, 165, 651-657, 1969.

Roberts, W. A., and R. H. Carlson, Ejecta studies, Project Sedan, Univ. Calif. Lawrence Rad. Lab., PNE-217P, 62 pp., 1962.

Rogers, A. E. E., M. E. Ash, C. C. Counselman, and I. I. Shapiro, Radar measurements of the surface topography and roughness of Mars, Radio Sci., 5, 465-473, 1970.

Sagan, C., and J. B. Pollack, Elevation differences on Mars, Smithson. Inst. Astrophys. Observ. Spec. Rep. 224, 45 pp., 1966.

Sagan, C., and J. B. Pollack, Elevation differences on Mars, J. Geophys. Res., 73, 1373-1387, 1968.

Tombaugh, C. W., A survey of long-term observational behavior of various martian features that affect some recently proposed interpretations, Icarus, 8, 227-258, 1968.

Urey, H. C., On the escape of water from Mars, Astronom. Soc. Pac. 68, 220-222, 1956.

Wells, R. A., Martian topography: Large-scale variations, Science, 166, 862-865, 1969.

Williams, Howel, Calderas and their origin, Unvv. Calıf., Bull. Dep. Gcol. Sci., 25, 239-346, 1941.

(Received August 10, 1970; revised September 14, 1970.) 